\title{
The Selective Reduction of $\mathrm{NO}_{x}$ with $\mathrm{NH}_{3}$ over Zirconia- Supported Vanadia Catalysts
}

\author{
S. Szakacs,a,b, G.J. Altena ${ }^{a}$, T. Fransenª, J.G. Van Ommen a and J.R.H. Ross ${ }^{a}, c$ \\ aFaculty of Chemical Technology, University of Twente, P.O. Box 217, 7500 AE \\ Enschede, The Netherlands
}

bCurrent address: Budapest 1023, Lukacs u.2, Hungary.

cCurrent address: University of Limerick, Plassey Technological Park, Limerick, Ireland.

\begin{abstract}
A series of sub-monolayer vanadia-on-zirconia catalysts have been prepared and the activities of these have been measured for the selective reduction of NO with $\mathrm{NH}_{3}$. It has been found that the activity per vanadium surface species depends on the square of the vanadium surface coverage. We therefore conclude that clusters of vanadia species on the surface of the catalysts are responsible for the de- $\mathrm{NO}_{\mathbf{x}}$ activity rather than isolated vanadia surface molecules.
\end{abstract}

\section{INTRODUCTION}

A wide variety of catalysts have been examined for their behaviour in the Selective Catalytic Reduction (SCR) of $\mathrm{NO}_{\mathbf{x}}$ using ammonia as reductant [1]. Most commercially-utilized formulations contain vanadium pentoxide $\left(\mathrm{V}_{2} \mathrm{O}_{5}\right)$ as the active component and the most frequently used support is titanium dioxide $\left(\mathrm{TiO}_{2}\right)$. The kinetics and mechanism of the $\mathrm{SCR}$ reaction have been studied in considerable detail by a number of authors, the greatest attention also having been given to the $\mathrm{V}_{2} \mathrm{O}_{5} / \mathrm{TiO}_{2}$ system [2-9]. However, there is still a lack of knowledge of those factors which influence the catalytic behaviour and of the nature of the active species on the catalyst surface. The aim of the work reported in this paper was to examine in some detail the behaviour of a somewhat lessstudied system, vanadia supported on zirconia $\left(\mathrm{ZrO}_{2}\right)$ [11-13]. We have paid most attention to the behaviour of sub-monolayer materials in order to study the effect of the concentration of surface vanadia species on the kinetics of the reaction. We conclude that clusters of vanadia species are more active per 
vanadium species than are isolated vanadium ions and that these sites have a different character to those found on the surface of bulk $\mathrm{V}_{2} \mathrm{O}_{5}$.

\section{EXPERIMENTAL}

The kinetic measurements reported here were carried out using a conventional flow apparatus, using an infrared detector (Unor $6 \mathrm{~N}$ ) for $\mathrm{NO}$ analysis and a back-titration system (using phosphoric acid with bromocresol green as indicator) for $\mathrm{NH}_{3}$ analysis. The materials of the system were Pyrex glass, stainless steel and teflon; the connecting tubing and valves were heated to prevent condensation of water. The reactor volume was small and so it was possible to use it to study changes occurring during the initial stages of the reaction and to examine the effect of changing the reaction conditions under steady-state operation. A series of zirconia-supported catalysts (Table 1) were prepared by the batch-adsorption method [14] using vanadyl (IV) acetylacetonate (Merck-Schuchard) dissolved in toluene. Two types of powdered zirconia were used: DynazirconF (monoclinic), supplied by Dinamic Nobel Co., and a sample from Zircar Products Inc., USA. The former had a total surface are of $63.5 \mathrm{~m}^{2} \mathrm{~g}^{-1}$ and the latter a surface area of $10.3 \mathrm{~m}^{2} \mathrm{~g}^{-1}$; the latter had been precalcined at $700^{\circ} \mathrm{C}$. After drying, the samples were calcined at $450^{\circ} \mathrm{C}$ for 2 hours. Several of the samples were calcined further at $700^{\circ} \mathrm{C}$. Details of the catalyst compositions and surface areas are given in Table 1; where appropriate, any deviations in the calcination procedure used are also given.

For comparison purposes, a series of additional catalysts were prepared. In order to examine the bahaviour of unsupported vanadia, a sample of pure vanadia free of micropores (Catalyst 1) was prepared by melting $\mathrm{NH}_{4} \mathrm{VO}_{3}$ (Merck, Zur Analyse) at $800^{\circ} \mathrm{C}$ in a $\mathrm{Pt}$ crucible. The resultant material was cooled to room temperature over a period of 3 hours. It was then added to distilled water and ground to a fine suspension; the suspension was filtered and calcined at $450^{\circ} \mathrm{C}$ for 2 hours. This material is referred to below as Catalyst 1. Two $\mathrm{TiO}_{2}$ supported catalysts (Ti-1 and Ti-2), both containing $0-3$ wt\% vanadium, were prepared by the batch adsorption method; the support for Ti-1 was uncalcined $\mathrm{TiO}_{2}$ (Degussa) while that for $\mathrm{Ti}-2$ was the same material but calcined at $750^{\circ} \mathrm{C}$ for 7 hours in air. The total surface area of the former was ca. $52 \mathrm{~m}^{2} \mathrm{~g}^{-1}$ and that of the latter was ca $30 \mathrm{~m}^{2} \mathrm{~g}^{-1}$. A further sample was prepared using a silica support ( $\mathrm{Si}-1)$.

\section{RESULTS AND DISCUSSION}

Table 1 lists the zirconia-supported catalysts used in the investigation, together with their vandium contents. In most cases, the vanadium contents were measured by X-ray fluorescence. 
Table 1 The $\mathrm{ZrO}_{2}$-supported vanadium oxide catalysts used in this work

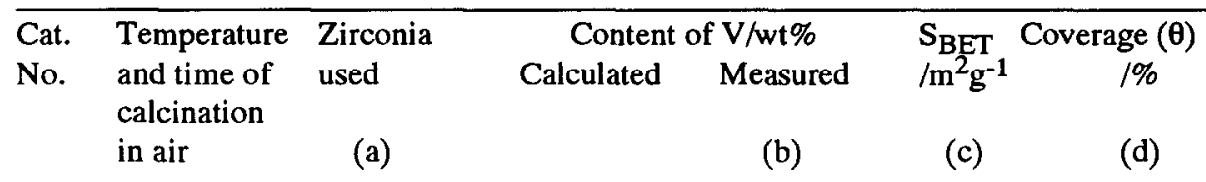

\begin{tabular}{|c|c|c|c|c|c|c|}
\hline 2 & $450^{\circ} \mathrm{C} / 2 \mathrm{~h}$ & D & 0.33 & 0.28 & 63.5 & 6 \\
\hline 3 & $450^{\circ} \mathrm{C} / 2 \mathrm{~h}$ & D & 0.50 & 0.45 & 63.5 & 9 \\
\hline 4 & $450^{\circ} \mathrm{C} / 2 \mathrm{~h}$ & D & 0.68 & 0.63 & 63.5 & 13 \\
\hline 5 & $450^{\circ} \mathrm{C} / 2 \mathrm{~h}$ & D & - & 0.93 & 63.5 & 19 \\
\hline 6 & $450^{\circ} \mathrm{C} / 2 \mathrm{~h}$ & D & - & 1.27 & 63.5 & 26 \\
\hline 7 & $450^{\circ} \mathrm{C} / 2 \mathrm{~h}$ & D & - & 1.59 & 63.5 & 33 \\
\hline 8 & $700^{\circ} \mathrm{C} / 13 \mathrm{~h}$ & D & 0.33 & - & 20.0 & 16 \\
\hline 9 & $700^{\circ} \mathrm{C} / 3 \mathrm{~h}$ & Z & 0.09 & 0.10 & 10.3 & 13 \\
\hline 10 & $450^{\circ} \mathrm{C} / 2 \mathrm{~h}$ & $\mathrm{Z}$ & 0.17 & 0.21 & 10.3 & 27 \\
\hline 11 & $450^{\circ} \mathrm{C} / 2 \mathrm{~h}$ & Z & 0.34 & 0.31 & 10.3 & 36 \\
\hline 12 & $450^{\circ} \mathrm{C} / 2 \mathrm{~h}$ & $\mathrm{Z}$ & - & 0.52 & 10.3 & 67 \\
\hline 13 & $450^{\circ} \mathrm{C} / 2 \mathrm{~h}$ & $\mathrm{Z}$ & - & 0.55 & 10.3 & 70 \\
\hline 14 & $700^{\circ} \mathrm{C} / 8 \mathrm{~h}$ & $\mathrm{Z}$ & 0.34 & - & 8 & 45 \\
\hline
\end{tabular}

(a) $\mathrm{D}=\mathrm{ZrO}_{2}$ from Dinamic Nobel; $\mathrm{Z}=\mathrm{ZrO}_{2}$ from Zircar Products Inc.

(b) Determined by $X$-ray fluorescence

(c) Determined by argon adsorption method [16]

(d) Assuming one $\mathrm{VO}_{2.5}$ unit occupies $10.3 \AA 2$.

These contents were in reasonable agreement measured with these calculated from the concentrations of the original solutions used for impregnation, assuming total adsorption. The surface coverages achieved are given in the last column of Table 1; these were calculated assuming that each $\mathrm{VO}_{2.5}$ or similar species was attached directly to the support and that a surface area of $10.3 \AA^{2}$ was required for each [15]. All the surface coverages corresponded to less than a complete monolayer. Figure 1 shows the typical start-up and steady-state behaviours of Catalyst 7 at three different temperatures. For the uppermost temperature $\left(275^{\circ} \mathrm{C}\right)$, data are given for two initial concentrations of ammonia. It can be seen that the catalyst took some ten minutes to reach stationary-state behaviour; during that period, the NO conversion was lower than the final value. The effect was less pronounced at the higher temperatures, indicating that it was probably not an experimental artefact but due to the gradual attainment of the optimum state of the catalyst. The steady state was also achieved more rapidly with the higher concentration of ammonia. It is therefore probable that the establishment of the active catalyst requires partial reduction of the surface 


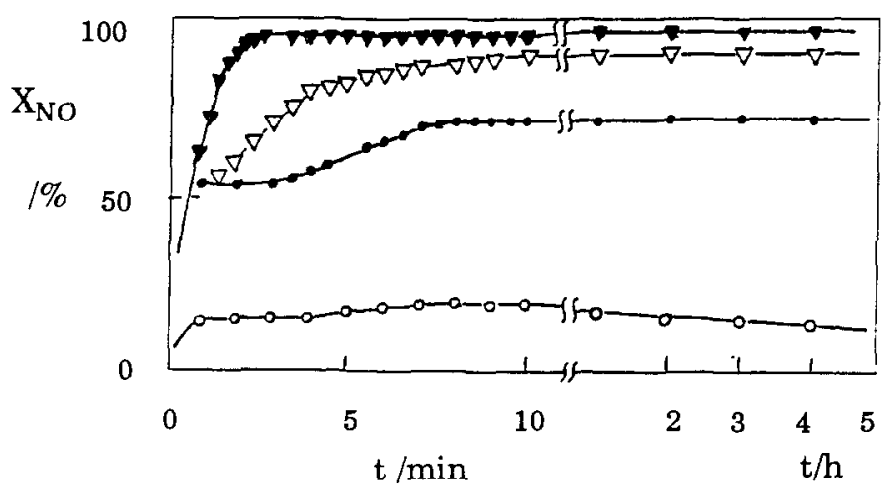

Figure 1 NO conversion $\left(\mathrm{X}_{\mathrm{NO}}\right)$ for Catalyst $7(0.1 \mathrm{~g})$ as a function of time on stream at four temperatures: $0,175^{\circ} \mathrm{C} ; \bullet, 225^{\circ} \mathrm{C} ; \nabla, \nabla, 275^{\circ} \mathrm{C}$. Reaction conditions:flow rate $=60 \mathrm{~cm}^{3} \mathrm{~min}^{-1} ; \mathrm{P}_{\mathrm{NO}}=1100 \mathrm{ppm}$;

$\mathrm{P}_{\mathrm{O}_{2}}=1.8$ vol\%; $\mathrm{P}_{\mathrm{NH}_{3}}=1200 \mathrm{ppm}$ for $\mathrm{o}, \nabla, \bullet$, and $200 \mathrm{ppm}$ for $\boldsymbol{\nabla}$.

species brought about by the reducing effect of the ammonia of the reaction mixture. The long-term conversions at higher temperatures remained constant over the duration of the experiments; however, there appears to have been a gradual loss of activity at lower temperatures.

Figure 2 shows some typical data for the steady-state conversion of NO as a function of reaction temperature for a series of catalysts which was selected in such a way that the same vanadium content was examined in each case; in the cases of the vanadia or zirconia materials, the coverages of the support by the vanadia ranged from $6 \%$ to $45 \%$ of a monolayer (see Table 1). The most active material was Ti-2 and this was closely followed by the $\mathrm{V}_{2} \mathrm{O}_{5} / \mathrm{ZrO}_{2}$ sample with the highest coverage (catalyst 14). The silica-supported catalyst was virtually inactive.

Figure 2 NO conversion $\left(\mathrm{X}_{\mathrm{NO}}\right)$ as a function of reaction temperature for various catalysts containing ca $0.3 \mathrm{wt} \% \mathrm{~V}$ : catalysts $14, \mathbf{\square} ; 11, \mathbf{\square} ; 8, \mathbf{\square} ; 2, \mathbf{\square} ; \mathbf{\Lambda}, \mathrm{Si}-1 ; \mathrm{c}$, Ti-1;•, Ti-2; standard conditions as Fig. 1.

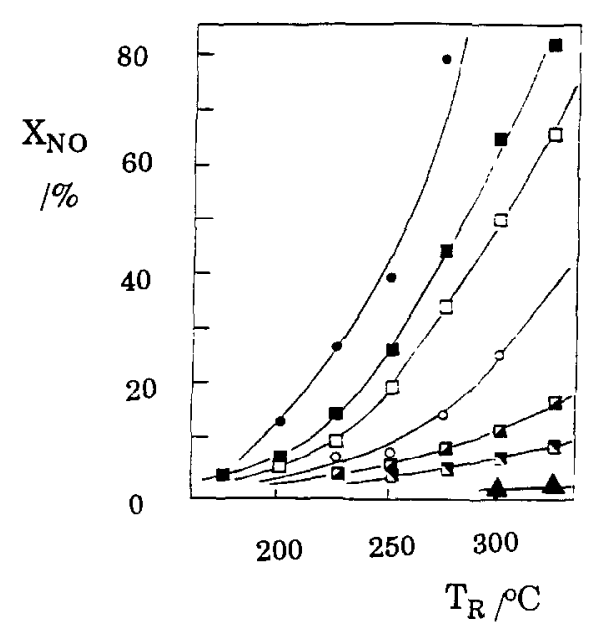



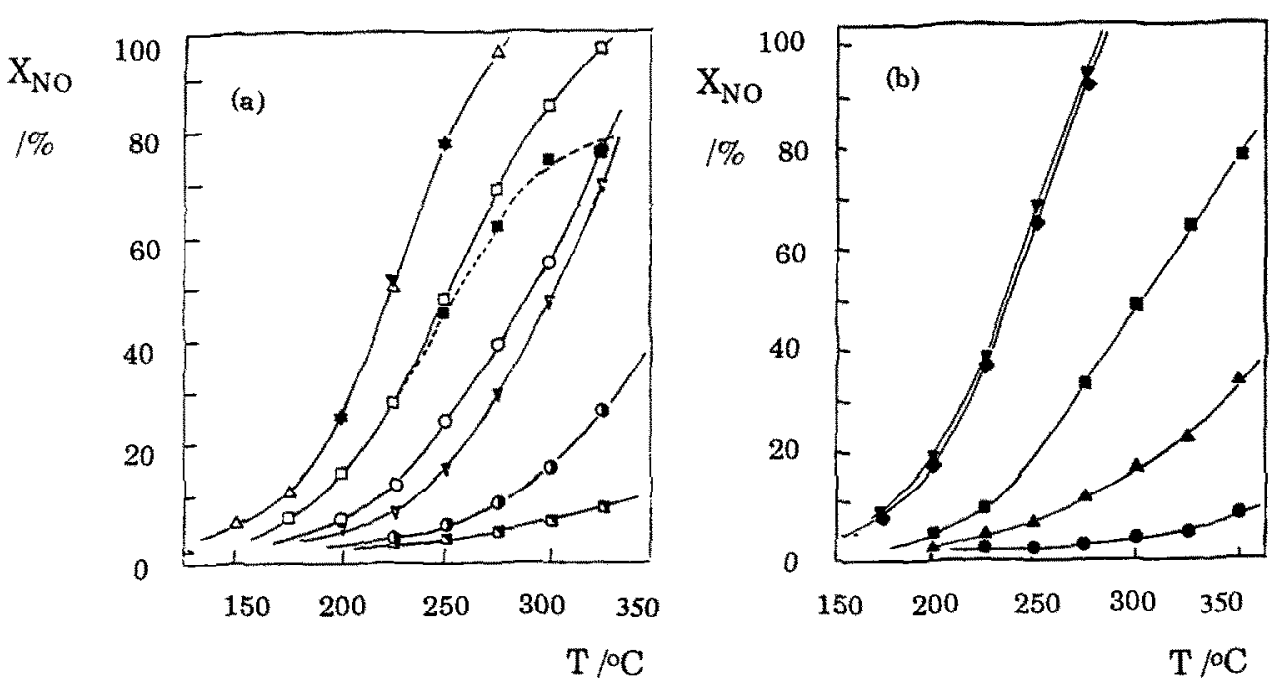

Figures $3 a$ and $b$ The conversion of $N O\left(X_{N O}\right)$ as a function of temperature for a series of $\mathrm{ZrO}_{2}$-supported vanadia catalysts: (Fig. 3a) $\Delta, 2 ; 0,3 ; \nabla, 4 ; 0,5 ; \boldsymbol{a}, \mathbf{n}, 6 ; \Delta$,

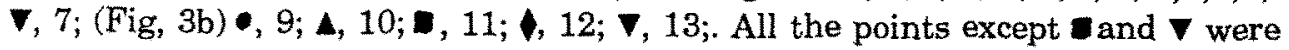
obtained under standard conditions (Fig. 1); $\mathbf{\varpi}, \mathbf{\nabla}: 1220 \mathrm{ppm} \mathrm{NH}$.

Figures $3 a$ and $b$ show the conversions of NO at various temperatues for the two series of catalysts supported on the zirconia with high (samples $2-7$ ) and low (samples $9-13$ ) surface areas respectively. The conversion increased markedly with increase in vanadia-content; the conversions for the low surfacearea materials (Fig. $3 \mathrm{~b}$ ) were higher than those of the equivalent high surfacearea materials (Fig.3a).

Figures 4 and 5 show the conversion of $\mathrm{NO}$ as a function of ammonia concentration for several catalysts at temperatures of $250^{\circ} \mathrm{C}$ and $300^{\circ} \mathrm{C}$ respectively. The order of reaction approached zero at higher ammonia concentrations, particularly at the lower temperature. Figure 6 shows log-log plots of the data obtained for the dependence on the partial pressure of NO for Catalyst 9. Similar results were obtained for other samples, including the unsupported material. The data all fit the equation:

$$
\mathbf{r}=\mathbf{k} \cdot \mathrm{P}_{\mathrm{NO}}{ }^{\alpha}
$$

with $\alpha=0.7 \pm 0.1$. The dependence of the rate on the partial pressure of oxygen was also examined; it was found that the rate was independent of $\mathrm{P}_{\mathrm{O} 2}$ as long as $\mathrm{P}_{02} / \mathrm{P}_{\text {NO }}$ was greater that about nine. That Eq.(1) was a reasonable representation of the data for two catalysts is shown in Figure 7 in which the values of $k$ calculated from the conversions using Equation (1) (assuming zero order for ammonia) as a function of reaction temperature are given for two of the catalysts using different catalyst weights. It can be seen that the data fit on single curves in a satisfactory manner. The values of activation energies calculated from these data were $60( \pm 4) \mathrm{kJ} \mathrm{mol}^{-1}$. 


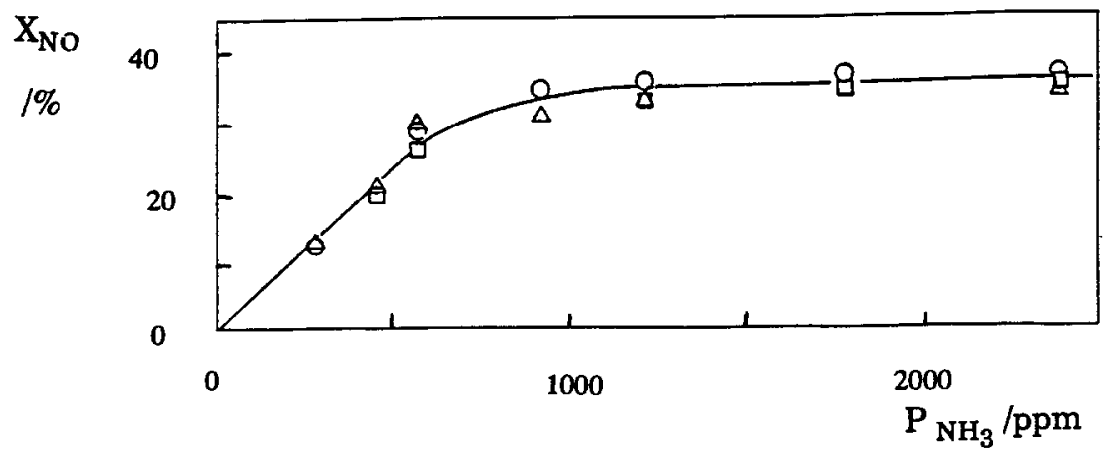

Figure 4 Conversion of $\mathrm{NO}\left(\mathrm{X}_{\mathrm{NO}}\right)$ at $250^{\circ} \mathrm{C}$ as a function of $\mathrm{NH}_{3}$ concentration with remaining conditions as Fig. $1 ; 0$, catalyst $1(0.128 \mathrm{~g}) ; \Delta$, catalyst $3(0.343 \mathrm{~g})$; o, catalyst $5(0.077 \mathrm{~g})$.

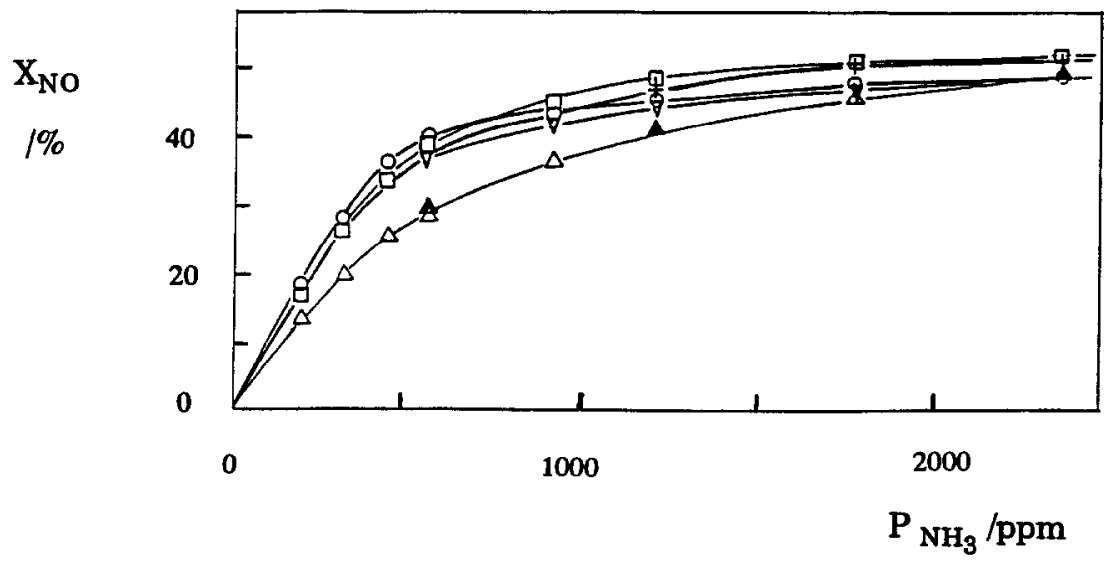

Figure 5 Conversion of $\mathrm{NO}\left(\mathrm{X}_{\mathrm{NO}}\right)$ at $300^{\circ} \mathrm{C}$ as a function of ammonia concentration; remaining conditions as for Fig 4; $\Delta, \Delta$, catalyst 1 (0.090 g); 0 , catalyst $3(0.132 \mathrm{~g}) ; \mathbf{n}$, catalyst $5(0.43 \mathrm{~g}) ; \nabla$, catalyst $9(0.100 \mathrm{~g}) ;+$, catalyst 1 $(0.063 \mathrm{~g}) ;+\mathrm{ZrO}_{2}(0.127 \mathrm{~g})$.

Figure 6 Plots of $\ln \left(\mathrm{X}_{\mathrm{NO}}\right)$ vs $\ln \left(\mathrm{P}_{\mathrm{NO}}\right)$ for data obtained using two reaction temperatures: $\bullet, 250^{\circ} \mathrm{C}$ and $\Delta, 300^{\circ} \mathrm{C}$; other reaction conditions as Fig. 1.

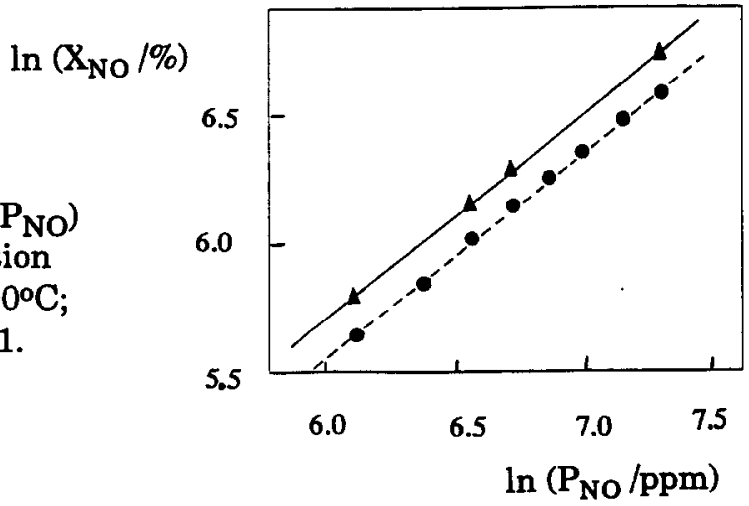


Figure 7 Rate constants calculated from Eq. 1 as a function of temperature for catalyst $1(0,0.054 \mathrm{~g} ; \Delta, 0.102 \mathrm{~g})$ and catalyst $2(\nabla, 0.051 \mathrm{~g} ; \bullet, 0.100 \mathrm{~g}$; o, $0.2000 \mathrm{~g})$; conditions as in Fig. 1 $\mathrm{k} / \mathrm{arb}$. units

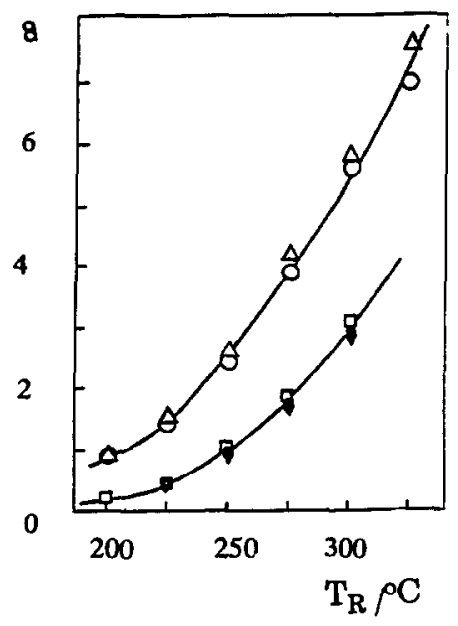

$\mathrm{k} / \mathrm{arb}$. units

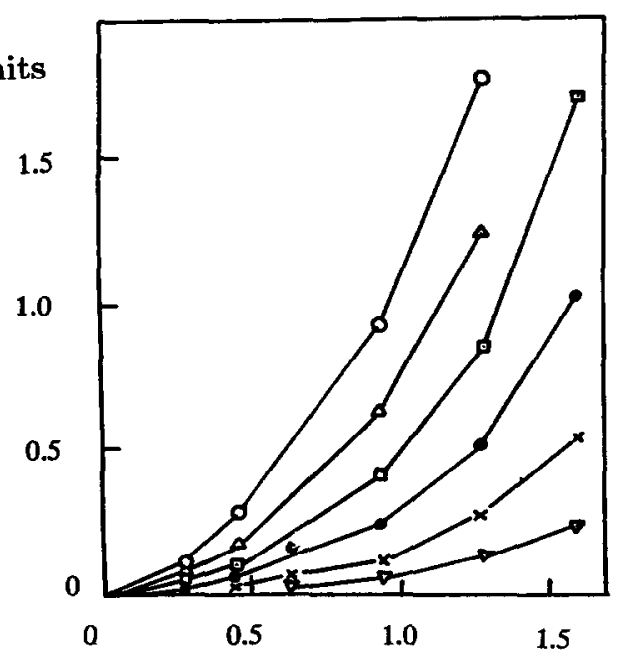

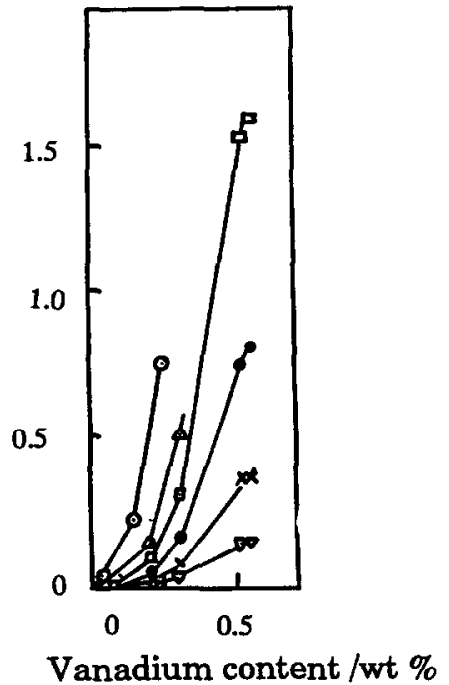

Figure 8 Calculated rate constants $(k)$ as a function of vanadium content for different reaction temperatures for two different zirconia supports: (a) surface area $63 \mathrm{~m}^{2} \mathrm{~g}^{-1}$ and (b) $12 \mathrm{~m}^{2} \mathrm{~g}^{-1} ; \nabla, 225^{\circ} \mathrm{C} ; \mathrm{x}, 250^{\circ} \mathrm{C} ; \bullet, 250^{\circ} \mathrm{C} ; \Delta, 275^{\circ} \mathrm{C} ; 0,300^{\circ} \mathrm{C}$.

In order to examine the effect of $\theta \mathrm{V}_{2} \mathrm{O}_{5}$ on the rate of reaction, the values of conversion of Fig. 3 were recalculated as $k$ values (using Eq. 1) and these values were plotted for each of the two supports as a function of $\theta \mathrm{V}_{2} \mathrm{O}_{5}$.for various reaction temperatures. The results are shown in Figure 8. It is clear that in neither case is the rate constant a linear function of $\theta_{V_{2}} \mathrm{O}_{5}$. Instead, the values of $\mathrm{k}$ are approximately proportional to the square of the vanadia concentration; ie. the rate is given by an expression of the form:

$$
\text { rate }=\mathrm{k}^{\prime} \cdot \theta \mathrm{V}_{2} \mathrm{O}_{5} \cdot \mathrm{P}_{\mathrm{NO}^{0.7}} \cdot \mathrm{P}_{\mathrm{NH}_{3}}{ }^{0}
$$


In order that we may explain the quadratic dependence on ${ }^{\theta} \mathrm{V}_{2} \mathrm{O}_{5}$, we therefore propose that the de- $\mathrm{NO}_{\mathbf{x}}$ reaction requires surface sites composed of at least two vanadia species in close proximity on the zirconia surface, presumably bridged by at least one oxygen species:

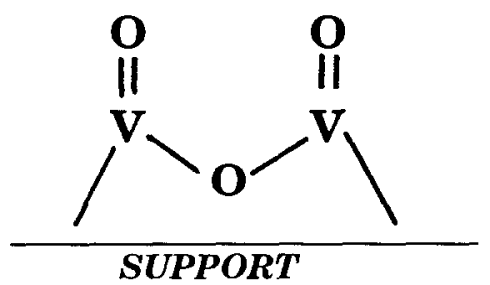

Such species are consistent with the mechanism proposed previously for $\mathrm{V}_{2} \mathrm{O}_{5} / \mathrm{TiO}_{2}$ catalysts [17]. They are utilised to dissociate ammonia molecules to form adjacently adsorbed $\mathrm{ONH}_{2}$ and $\mathrm{OH}$ species attached to vanadium species; the $\mathrm{ONH}_{2}$ species can then react with $\mathrm{NO}$ to form $\mathrm{N}_{2}$ and water, leaving behind the original $\mathrm{V}=\mathrm{O}$ species. The reaction scheme [17] is also consistent with the suggestion that partial reduction of the catalyst may be occurring in the early stages as it also presupposes the presence on the surface of $\mathrm{V}^{3+}$ species. Clearly, the close proximity of the support to these sites will mean that the support exerts some influence on the behaviour of the oxygen species attached to the vanadium. Hence, it is to be expected that unsupported vanadia would behave differently to the zirconia-supported material. That this was so was demonstrated by comparing the apparent activation energies for the de- $\mathrm{NO}_{\mathbf{x}}$ reaction over the $\mathrm{V}_{2} \mathrm{O}_{5} / \mathrm{ZrO}_{2}$ catalysts $\left(60.1 \pm 4.0 \mathrm{~kJ} \mathrm{~mol}^{-1}\right)$ with that for the unsupported $\mathrm{V}_{2} \mathrm{O}_{5}$, Catalyst 1 (40.3 kJ mol-1).

The requirement of clusters of vanadia species on the surface of a de- $\mathrm{NO}_{\mathbf{x}}$ catalyst may be general for all types of support if the scheme referred to above [17] can also be applied generally. However, there does not appear to have been a systematic study similar to the one described here in which the kinetics of the deNO $_{\mathbf{x}}$ reaction have been examined as a function of the loading for samples with less than a monolayer of vanadia. (It should in this context be noted that the data presented in Figure 2 for two titania-supported catalysts with the same loading of vanadium on two titania supports but with different surface areas indicates that there are also similar dependences on vanadia coverage for those samples.) It is interesting to note that since the presentation of this paper, Deo and Wachs have presented results which show that the specific activities of vanadia-titania catalysts for the oxidation of methanol are not dependent on the loadings of the vanadia on that support [18]. It would thus appear that the de$\mathrm{NO}_{\mathrm{x}}$ reaction is structure sensitive whereas methanol oxidation is not; the methanol reaction would appear to occur on single vanadia sites which are relatively unaffected by the geometry and nature of the surrounding species. 


\section{CONCLUSIONS}

From an examination of the activities of a series of sub-monolayer vanadia-onzirconia calalysts for the selective reduction of $\mathrm{NO}_{\mathrm{x}}$, it is concluded that the rate of that reaction depends on the square of the coverage of the zirconia by vanadia species. It is therefore concluded that the active site requires two vanadia species in close proximity to one another for the dissociation of the ammonia. These results are in agreement with a model proposed earlier[17].

\section{REFERENCES}

1 H. Bosch and F. Janssen, Catal. Today, 2 (1988) 369.

2 M. Takagi, T. Kawai, M. Soma, T. Onishi and K. Tamaru, J. Catal., 50 (1977) 441.

3 S.C. Wu and K. Nobe, Ind. Eng. Chem. Prod. Res. Dev., 16 (1977) 136.

4 M. Inamata, A. Miyamoto and Y. Murakami, J. Catal., 62 (1980) 140.

5 A. Miyamoto, K. Kobayashi, M. Inomata and Y. Murakami, J. Phys. Chem., 86 (1982) 2945.

6. A. Miyamoto, Y. Yamazaki, T. Hottori, M. Inomata and Y. Murakami, J. Catal. 74 (1982) 144.

7. M. Farber and S.P. Harris, J. Phys. Chem., 88 (1984) 680.

8. C.U.I. Odenbrand, S.T. Lundin and L.A.H. Andersson, Appl. Catal., $18,(1985) 335$.

9. H. Bosch, J.J.G. Janssen, F.M.G. van der Kerkhof, J. Oldenziel, J.G. van Ommen and J.R.H. Ross, Appl. Catal., 25 (1986) 239.

10. S. Szakacs, Thesis, Technical University of Budapest, 1972.

11. Y. Murakami, M. Inomata, K. Mori, T. Ui, K. Suzuki, A. Miyamoto and T. Hattori, Stud. Surf. Sci. Catal., 16, (Preparation of Catalysts, III) (1982) 531.

12. S. Okazaki, M. Kunasaka, J. Yoshida and K. Kosaka, Ind. Eng. Chem., Prod. Res. Dev., 20 (1981) 301.

13. T. Iizuka, H. Ikeda and S. Okazzaki, J. Chem. Soc., Farad. Trans. I, 82 (1986) 61.

14. J.G. van Ommen, H. Bosch, P.J. Gellings and J.R.H. Ross, Stud. Surf. Sci. Catal., 31 (Preparation of Catalysts IV) (1987) 151.

15. F. Roozeboom, T. Fransen, P. Mars and P.J. Gellings, Z. Anorg. Allg. Chem. 449 (1979) 25.

16. H. Bosch and A. Peppelenbos, J. Physics E., Sci. Instruments, 10 (1977) 605.

17. F.J.J.G. Janssen, F.M.G. van den Kerkhof, H. Bosch and J.R.H. Ross, J. Phys. Chem. 91 (1987) 5921, 6633; see also article by F. Janssen and R. Meijer, Catal. Today, this issue.

18. G. Deo and I.E. Wachs, ACS Petr. Div. Preprints, 37 (1992) 1062. 